\title{
Establishing a Pacific Voice in the Climate Change Negotiations
}

\section{George Carter}

When asked about the greatest challenge to global climate change negotiations at the United Nations Third Small Islands Developing States Conference in 2014, the leaders of three Pacific Island states expressed similar sentiments. Enele Sopoaga, Prime Minister of Tuvalu, said that 'Pacific negotiators need to be in sync at the UNFCCC'; Tony de Brum, Minister of Foreign Affairs of Marshall Islands, asserted that 'there has been a failure of traditional diplomacy at the UN ... we need a new brand of diplomacy ... one voice diplomacy'; and President Anote Tong of Kiribati argued 'we need to establish alliances that are non-traditional, that serve our best interest'. These responses echo the frustration of Pacific leaders at the state of current negotiations as they prepare for the Conference of the Parties (COPs) in Paris, 2015. The COPs 2015 is especially significant as it attempts to produce a new global climate change action agreement for post-2020.

For almost 25 years, the global climate change regime has been an arena of complex and multifaceted diplomacy involving seemingly endless negotiations on a wide range of issues with a plethora of actors (state, civil society and private 
businesses). ${ }^{1}$ The climate regime is based on the 1992 United Nations Framework Convention on Climate Change (UNFCCC), which commits its 196 state parties to reduce greenhouse gas emissions under the mechanisms of the Kyoto Protocol. Despite the various negotiation impasses, the constant contact of negotiators has allowed for innovative forms of climate diplomacy. An important aspect of climate diplomacy, and a complementary bargaining tool to a state's climate policy position, are the political groupings or interstate coalitions to which they belong. As reflected in the above responses, Pacific leaders are increasingly placing a strong emphasis on Pacific coalitions or political groupings as a means to accentuate a Pacific voice in the climate change regime at the global level.

This chapter explores the work of Pacific Island states in establishing a Pacific voice at global climate change negotiations. It seeks to draw out several trends in the academic literature relevant to Pacific states' participation in the UNFCCC, through interstate coalitions. For the student of Pacific diplomatic studies and international relations, the general literature is disappointing in its lack of attention to the Pacific Islands experience. To paraphrase Carsten Holbraad, the Pacific Islands have always been objects of international relations theory building, and never the subjects of analysis (Holbraad 1971, p. 78). In piecing together the trends and behaviour of Pacific state participation through coalitions, a student of diplomatic studies finds not only the employment of innovative tools of diplomacy, but also exciting avenues of future empirical research.

There are many coalitions with which the 14 Pacific Island states that are party to the convention are associated. ${ }^{2}$ While it is the prerogative of a state to be associated with any grouping, this raises two important questions. Firstly, why is it important for Pacific states to join coalitions? Secondly, what is the advantage gained from joining multiple coalitions in the regime? This paper will address these questions in three parts. The first part of this paper will outline why coalition blocs are an integral part of the climate change regime. The second part will provide an overview of the various blocs with which Pacific states are associated. Finally, the paper will focus on the benefits of joining multiple coalition blocs for Pacific Island states.

\footnotetext{
1 On average, over 7,000 country delegates and 4,000 media representatives attend the COPs. In smaller negotiations during the year there are on average 2,000 participants. These figures do not include the various UN agencies staff. Over 1,500 observer organisations have been registered for accreditation in the negotiations. 2 The 14 Pacific Islands states that are party to the UNFCCC are: Cook Islands, Fiji, Federated States of Micronesia, Kiribati, Marshall Islands, Nauru, Niue, Palau, Papua New Guinea, Samoa, Solomon Islands, Tonga, Tuvalu, and Vanuatu.
} 


\section{Coalition Diplomacy in the Climate Change Regime}

\section{Coalition Diplomacy Literature}

The study of coalitions has high theoretical and practical significance for the discipline of international relations. Its theoretical contributions have critical impact on the stability (or otherwise) of the international system (Narlikar 2003, p. 12). There already exists a vast amount of scholarship devoted to analysing the implications of multipolar versus bipolar alliance structures and coalitions of the willing, of war and peace. ${ }^{3}$ More importantly, the policy significance of interstate coalitions lies in the fact that they provide opportunities for member countries. As Christophe DuPont argues, there are two core functions of coalitions. Firstly, coalitions function as a means for maximising bargaining power for its members (Dupont 1996, p. 49). Secondly, coalitions function as a means for managing complexity of processes and issues within a regime where a common platform that incorporates the minimal demands of each coalition member is easier to handle and negotiate than the sum of individual items (Dupont 1996, p. 49). These two core functions are especially important for small countries with limited negotiation resources and political clout in climate negotiations, such as Pacific Island countries.

Although considered to be a significant part of the UNFCCC regime, coalitions are relatively understudied. Coalitions are mentioned briefly in the neoliberal regime literature by academic negotiators such as a Yamin and Depledge (2004) and Depledge (2005). Within the burgeoning area of global environmental politics, the focus of research has mainly been on individual state bargaining, asymmetrical power relations of states (polluters), and non-Annex I states (Bailer 2012), especially theorising conditions for a global climate change agreement. At best, the limited literature available compares the strategies of climate coalitions with those in the areas of trade, the international criminal court (Wallbott and Deitelhoff 2012), or coalitions of epistemic communities and non-government organisations (NGOs) (Gough and Shackley 2001). Recent studies on the issue of climate justice (Audet 2013) and the emergence of post-Kyoto coalition blocs (Blaxekjær and Nielsen 2014) emphasise a complex landscape of political coalitions within the regime.

Only a handful of studies highlight the work of Pacific state participation in coalitions of the UNFCCC, but these studies are primarily focused on the broader Alliance of Small Island States (AOSIS). Ashe et al. (1999), Chasek (2005) and Betzold (2010), for example, have analysed the influence of AOSIS, especially

3 See the work in alliance and coalition theories by Waltz (1979), Walt (1987), Morgenthau (2003), Snyder (1997), and Sheehan (1996). 
regarding agenda setting in the early days of the regime. A more recent paper by Betzold, which highlights intra-bloc diplomacy, finds that although AOSIS continues to function as a group, incidents of internal disagreements have prompted a questioning of its cohesiveness (Betzold et al. 2012). While this body of work on AOSIS is useful in producing some insights into the work of Pacific Island states in negotiations, it does not fully uncover the internal politics of the group. Most importantly for our purposes here, the perspectives of Pacific negotiators are hidden by the strong leadership voice of Caribbean countries.

\section{Coalitions in UNFCCC}

Coalitions are an integral part of the climate change regime, as it would be logistically impossible to conduct negotiations among the 196 individual country delegations. The existence of coalitions, some of which speak with a common voice, helps to streamline the negotiation process and transaction costs (Gupta 2000, p. 34). Their very presence leads to a dual structure in the climate change regime: issues are negotiated at the coalition level first, before common positions are presented in a COPs and Subsidiary Bodies (SBs) meeting. These coalitions inadvertently become clearinghouses or filters for key positions and rallying support for major submissions.

Despite the prominence accorded to the work of the coalitions by the parties themselves, there are no hard and fast rules or formal processes for establishing a negotiation coalition. States may simply decide to do so, and then usually notify the COPs bureau, SBs, or secretariat of their actions (Gupta 2000, p. 35). Without a registry of blocs, the precarious ad hoc nature of these arrangements makes the tracking of coalitions difficult. The well-known coalitions document their existence through plenary statements, submissions, media releases and engagement in public debate. Those coalitions that are not well documented, on the other hand, are often involved in secret side-door or back-room negotiations. Although such coalitions are widely known and can be useful, they can also be detrimental, as evidenced by the Copenhagen COP 15, where secret dealings changed and derailed negotiations. ${ }^{4}$

Coalition blocs are intrinsic to the climate change regime, with UNFCCC article 3 dividing the 195 Parties into two major camps: Annex I countries (developed countries) and non-Annex I countries (developing countries). In recognising that developed countries are principally responsible for the current high levels of greenhouse gas emissions in the atmosphere as a result of more than 150 years of industrial activity, the protocol places a heavier burden on developed nations under the principle of common but differentiated responsibilities (UNFCCC n.d.). This north-south divide, also referred to as 'the firewall', becomes the basis upon which political groupings are formed. 


\section{Pacific States in UNFCCC Coalitions}

There are 21 coalition blocs that have actively participated in the climate change regime. The membership of states within these blocs is varied. Some blocs comprise only Annex I countries or non-Annex I countries, while others include both. Of the 21 coalition blocs, there are six blocs associated with one or more Pacific parties. As climate change negotiations progress with little action improving the situation for Pacific states, Pacific leaders are responding by creating new Pacific blocs in an attempt to create a united Pacific voice in the hope of affecting real change in global climate change negotiations. This section will provide a brief outline of the six traditional coalition blocs of which Pacific states are currently members before discussing the emergence of new Pacific blocs.

\section{Table 17.1: Coalition Blocs in UNFCCC Negotiations}

\begin{tabular}{|c|c|c|}
\hline Annex I & non-Annex I & Both Annex I and non-Annex I \\
\hline $\begin{array}{l}\text { Economies In } \\
\text { Transition (EIG) }\end{array}$ & African Group (AG) & $\begin{array}{l}\text { Environmental Integrity Group } \\
\text { (EIG) }\end{array}$ \\
\hline $\begin{array}{l}\text { European } \\
\text { Union (EU) }\end{array}$ & Alliance of Small Island States (AOSIS) & $\begin{array}{l}\text { Cartagena Dialogue for } \\
\text { Progressive Action (CD) }\end{array}$ \\
\hline \multirow[t]{13}{*}{$\begin{array}{l}\text { Umbrella } \\
\text { Group (UG) }\end{array}$} & $\begin{array}{l}\text { Bolivarian Alliance for the Peoples of our } \\
\text { America (ALBA) }\end{array}$ & Durban Alliance (DA) \\
\hline & Central American Integration System (SICA) & \\
\hline & Central Asia, Caucasus and Moldova (CACAM) & \\
\hline & Coalition of Rainforest Nations (CfRN) & \\
\hline & League of Arab States (LAS) & \\
\hline & Least Developed Countries (LDC) & \\
\hline & G77 and China (G77) & \\
\hline & $\begin{array}{l}\text { Organisation of Petroleum Exporting Countries } \\
\text { (OPEC) }\end{array}$ & \\
\hline & Brazil, China, South Africa, India (BASIC) & \\
\hline & $\underline{\text { Climate Vulnerable Forum (CVF) }}$ & \\
\hline & $\begin{array}{l}\text { Mountains Landlocked Developing Countries } \\
\text { (MLDC) }\end{array}$ & \\
\hline & Like Minded Developing Countries (LMDC) & \\
\hline & $\begin{array}{l}\text { Association of Independent Latin American and } \\
\text { Caribbean Countries (AlLAC) }\end{array}$ & \\
\hline
\end{tabular}

Note: The coalitions which some or all of the 14 Pacific states are involved with appear as underlined. Source: The list is attributed to research by Blaxekjær and Nielsen (2004) which focuses on coalitions that arose after COPs Copenhagen 2009. 


\section{G77 and China}

Founded in 1964, in the context of the UN Conference on Trade and Development, G77 and China has been active since the early days of the convention. Of the 134 members in the group, 10 are from the Pacific: Fiji, Federated States of Micronesia, Kiribati, Marshall Islands, Nauru, Papua New Guinea, Samoa, Solomon Islands, Tonga, and Vanuatu.

The membership dynamics of the group are diverse, ranging from vulnerable small island states, least developing countries, and oil exporting countries, to large and middle income nations, each with differing interests on climate change issues. Despite this, the G77 remains the most important and powerful coalition. The group develops common positions on substantive issues by consensus: if there is no consensus, there is no position. The chair of the group is the first to take the floor in the main negotiations and presents the common positions.

The role of chair rotates annually and although it is a highly respected position, not all countries feel able or willing to take it on due to the economic and institutional resources required, the difficulty of bringing members to a common position, and the fact that the G77 chair may have to stand against some powerful countries, which could trigger wider political repercussions (Gupta 2000, p. 36). While countries such as Papua New Guinea and Samoa chaired G77 subsidiary bodies, the landmark year for Pacific leadership in the group came in the form of Fiji's chairmanship of the whole G77 in 2013.

\section{Least Developed Countries}

The Least Developed Countries (LDC) bloc was formed in 1971 as an offshoot from a UN categorisation of countries. Of the 48 countries in this group, only Tuvalu, Solomon Islands, Kiribati and Vanuatu are from the Pacific. (Samoa left the group following its LDC graduation in 2014).

The bloc has become increasingly active in the climate change process, often working to defend its particular interests - with regard to vulnerability and adaptation to climate change, for example(UNFCCC n.d.). The bloc works together at the intergovernmental negotiations under the UN Framework Convention on Climate Change with two aims. The first is to demand that wealthier nations act in accordance with their responsibility for creating the problem and their capability for addressing it. The second aim is to play a leadership role in global efforts to prevent dangerous climate change (Least Developing Countries Group n.d.). 


\section{Alliance of Small Island States}

Established in 1990, the Alliance of Small Island States (AOSIS) has and continues to be the premier bloc in the formal negotiations with close resonance to Pacific Island needs. It comprises 44 small island states and low-lying coastal states that are highly vulnerable to climate change. All 14 Pacific Island countries are part of the coalition, with American Samoa and Guam having observer status. Although the diverse membership of AOSIS derives from the Pacific, Caribbean and Indian Oceans, they are united by the common immediate threat posed to their survival by climate change.

The bloc proved instrumental in shaping the regime when it prepared the original draft of the Kyoto Protocol, advocating for 20 per cent cuts in carbon dioxide emissions from 1990 levels by 2005. Famously quoted as the 'moral conscience' of the negotiations, the ad hoc lobby group gives voice to the Small Island Developing States (SIDS) on environmental matters and climate change threats. The bloc is the main focal point for many Pacific negotiators in terms of technical resource and capacity support. Its ambassadors in New York meet periodically throughout the year to be apprised on positions, but key discussions occur in the weeks prior to and during the negotiations. One of the most notable contributions of the bloc has been successful lobbying for SIDS as special case in the Rio Summit of 1992 that led to the establishment of the SIDS conferences.

\section{Coalition of Rainforest Nations}

The Coalition of Rainforest Nations (CfRN) was founded in 2004 and brings together tropical rainforest developing countries to collaboratively reconcile forest stewardship with economic development. Of the 41 members, Fiji, Samoa, Solomon Islands, Vanuatu and Papua New Guinea are drawn from the Pacific.

The coalition operates as a forum to facilitate consensus among participating countries on issues related to the domestic and international frameworks for rainforest management, biodiversity conservation, and climate stability. The work of the bloc has been instrumental in the establishment of the Reducing Emissions from Deforestation and Forest Degradation (REDD) program, which was vigorously negotiated as the Bali Action Plan. The success of the REDD program owes much to the tactical plea of Papua New Guinea Prime Minister Michael Somare and Papua New Guinea Special Envoy Kevin Conrad in the Bali COPs of 2007. The breakthrough moment when Kevin Conrad called out to the United States, 'If you're not willing to lead, then get out of the way', has been described as 'the mice that roared' incident (von videoarchitekt 2007). 


\section{Climate Vulnerable Forum}

The Climate Vulnerable Forum (CVF), founded a month before COPs Copenhagen in 2009, is an international partnership of countries highly vulnerable to a warming planet. The forum is premised on the idea of a south-south cooperation platform for participating governments to act together to deal with global climate change (Climate Vulnerable Forum n.d.). Kiribati, Tuvalu and Vanuatu are within its 20-member country grouping.

The forum of highly vulnerable developing countries argues that they are already experiencing the negative effects of climate change. In 2010, Kiribati was the chair of the CVF and hosted the Tarawa Climate Change Conference, which was instrumental in bringing together Pacific states and their major development partners to sign the Ambo Declaration. The 12 signatories to this declaration were Kiribati, the Solomon Islands, Tonga, the Republic of the Maldives, Cuba, Brazil, Fiji, Japan, China, the Marshall Islands, New Zealand and Australia (Packard 2010).

\section{Cartagena Dialogue for Progressive Action}

Established in 2010, the Cartagena Dialogue for Progressive Action (Cartagena Dialogue) was formed after the breakdown of the Copenhagen COPs, recognising the need to rebuild trust between developed and developing countries. The group continues to meet outside formal UNFCCC negotiations. While its members claim that it is not a political bloc, the dialogue provides a platform for delegates from developed and developing countries to have frank discussion to better understand each other's positions and find areas of possible middle ground. This fluid membership is useful, as developing countries apparently find it difficult to be too closely associated with developed countries in negotiations due to formal group memberships and a sense of loyalty to G77 (Blaxekjær and Nielsen 2014, p. 4). Of the countries involved in the dialogue, only Samoa and Marshall Islands have been actively involved. The 2014 Cartagena Dialogue was held in Marshall Islands and focused on opportunities to break the international deadlock and find common position for a 2015 binding agreement (Islands Business 2014).

\section{The Emergence of 'Pacific' Coalitions}

In the past five years, there have been new developments in the political landscape of coalition blocs in relation to the Pacific Island countries. While the six groups described above appear to remain cohesive and functioning, new groupings have emerged due to intra-bloc disagreements. As one lead negotiator states, the traditional blocs 'have not been sufficient in addressing our Pacific 
needs ... the particular issues of coral islands nations are drowned amongst the bigger tropical rainforest, harbour and oil-producing nations' (Pacific negotiator 2014). These groupings exist on the fringes of the six traditional blocs, and strive to provide a more powerful voice for the Pacific in negotiations. The two new Pacific climate change blocs are Pacific SIDS and the Coalition of Atoll Nations.

\section{Pacific SIDS}

The advent of the Pacific SIDS (PSIDS) group in the climate regime is arguably a natural progression. PSIDS is a consortium of ambassadors of the 12 Pacific embassies based in New York, whose work encompasses the major thematic areas of the UN. The group was once the Pacific Islands Forum contact group in New York, however, in a show of solidarity towards Fiji, it continued its work with less Australian and New Zealand influence. Since 2007, PSIDS has grown organically to be the main Pacific grouping whose work encompasses the major thematic areas of the UN. While it is not clear when the group officially became involved in the climate debate, the first submission by the group to a Subsidiary Body meeting came in 2009 (just before Copenhagen). Since then, the PSIDS has been a clearing house for key joint positions of the Pacific states for AOSIS and subsequently for G77. According to one negotiator, there is an increasing feeling amongst Pacific leaders that PSIDS should become more vocal as a bloc in the regime (Pacific negotiator 2014).

\section{Coalition of Atoll Nations on the issue of Climate Change}

In July 2014, a new grouping was formed by 'front-line states' out of further frustration with the results of negotiations. The Coalition of Atoll Nations on the issue of Climate Change (CANCC) was the initiative of President Anote Tong. It comprises four atoll nations: Kiribati, Tuvalu, Marshall Islands, and the Maldives from the Indian Ocean. Their positions revolve around the rhetoric of atoll nations being in the frontline of the impacts of climate change and who consider themselves as the early warning system for the rest of the world. As one negotiator argued: 'Time after time, coral atoll nations have supported the work of the blocs, [but] because of our small populations (and bureaucratic incapacities) we are continually left out of climate financing initiatives and have to be content with only small pilot projects' (Pacific negotiator 2014). The group remains committed to pushing legally binding agreements and ambitious targets at the global level, and for easier access to resources for the 'smallest of small island nations'. The ultimate goal of the group is for UN special recognition in the convention for coral atoll nations (as in the case of AOSIS pursuing SIDS as a special case). 


\section{Benefits from Coalition Diplomacy}

The continued involvement of Pacific states in various coalition blocs and the growth of new groupings is testament to growing Pacific agency within the regime. Notwithstanding the work of individual country delegations, association with the blocs has not only empowered their positions, but has developed their diplomatic finesse. The many diplomacy lessons and benefits that can be derived include access to a wide network of negotiators, development in climate leadership, and engagement in climate public diplomacy.

\section{Negotiators Network/Service}

Through associations with these groupings in a year-long calendar of negotiations, it is only natural that a network of negotiators is established. The typical Pacific negotiator is no longer someone from the Ministry of Foreign Affairs. Coalitions are able to bring together a plethora of interested and needed actors from country delegations (including prime ministers, ambassadors, ministries of foreign affairs, environment and other national agency officials), scientists, regional organisation officials (such as Secretariat of the Pacific Regional Environment Programme, Secretariat of the Pacific Community, and Pacific Islands Forum Secretariat), environmental NGOS, international lawyers (such as the Foundation for International Environmental Law and Development), academics, and media. As a result, Pacific delegates are able to talk 'climate speak' fluently in the big negotiations (Betzold 2010, p. 141).

This constant contact of members can easily be mistaken for a global foreign service of negotiators. Armed with countless emails of text drafts and issue papers, they travel from the Pacific Islands to Bonn (for the SBs) and then to some metropolitan city (for the COPs), while their base remains at the UN headquarters in New York. The daily dialogue, bargaining, and instructions on procedural matters are delivered from ambassadors in New York. It is now common practice for each country to have at least one or two permanent negotiators (other than the ambassador) focused on climate change. Institutional knowledge is key, and rotation of personnel is thus not only a step back for a country, but also for coalitions.

To enhance the capacity of country and lead coalition negotiators, the groups have funded private firms that specialise in multilateral negotiations. The G77, LDC, CfRN and AOSIS groupings have all facilitated research, assembled advisory capacity, undertaken policy development, coordinated economic and technical regulatory frameworks, and overseen implementation. While the annual work 
of negotiators may be entrenched in what Chasek and Rajamani (2003, p. 257) call 'text diplomacy', they are unconsciously creating both a diplomatic culture and a network of Pacific negotiators.

\section{Climate (Diplomatic) Leadership}

A defining theme that resonates through the blocs is the attention to climate leadership. The concept of climate leadership evokes a call to immediate action to address the complex issues surrounding climate change by charting a course through global agreement. To paraphrase a top UNFCCC official, climate change is a challenge for all peoples and generations, and it calls on leaders to lead by example and leave a legacy for future generations (Figueres 2014).

While the concept has been a fundamental message in the rhetoric of Pacific leaders since the convention was established, their participation in the blocs has enabled them to influence global consciousness. Pacific statesmen and ambassadors have been chairs of various blocs - such as Vanuatu's Robert van Lierop, Samoa's Tuiloma Neroni Slade, Tuvalu's Enele Sopoaga, Nauru's Marlene Moses (for AOSIS), Papua New Guinea's Michael Somare, Kevin Conrad and Robert Aisi for the CfRN, and most recently Fiji's Ratu Inoke Kubuabola and Peter Thomson for the G77 Plus China. Although individual chairs have brought a unique style of leadership to the coalitions, it is undeniable that the increased participation of Pacific leaders in the coveted role of chair has instilled in the groupings, and the regime as a whole, more attention to the vulnerability of the Pacific Island states.

In line with recent developments of Pacific-only negotiating blocs, there has been a flurry of shuttle diplomacy within the region. With the impending demand for a new agreement in Paris in 2015, Pacific leaders have sought to increase regional and global awareness by lobbying in, and through, multiple arenas. Pacific leaders had no hesitation in raising climate change as a key issue in dialogues with President Francois Hollande of France, Prime Minister Narendra Modi of India, and Chinese President Xi Jinping, during their visits to the Pacific in 2014. At the UN Third SIDS 2014 meeting, Pacific leaders made sure that they negotiated to have the issue enshrined in the S.A.M.O.A Pathway outcome document (UN 2014), and urged the 4,500 participating representatives - from government, business, NGO, and epistemic organisations - to contribute to a legally binding agreement in Paris.

The Marshall Islands hosted the Cartagena Dialogue in 2014 and the PIF leaders summit in 2013, both important forums that brought leaders, negotiators and scientists to witness the impact of climate change first hand in the 'frontline states'. 'It was my first time on an atoll', stated Swedish Climate Change Ambassador, Anna Lindstedt. 'It was an eye-opener. It's not until you see it 
for yourself that you understand the situation (of islands)' (Johnson 2014). The Majuro Declaration of Climate Leadership, the first document of its type, which attempts to encourage Pacific forum leaders and post-dialogue partners to list specific commitments on greenhouse gas emissions, was a key document in both the Forum Leaders Summit and the Cartagena meeting. Called the 'Pacific gift' to the world by Marshall Islands Foreign Minister Tony de Brum, the declaration is a draft of the Pacific region's commitments that is intended to be a platform for an upward spiral of action to urgently address reduction of greenhouse gases.

\section{Climate Public Diplomacy}

Beyond the lobbying in multilateral meetings, dialogues, and, in some cases, in airport and hotel lounges, the coalitions have acknowledged the need to reach out to citizens. With the advent of new information technology allowing mass communication, many individuals and interested groups have become more connected than ever to the progress of the negotiations. Rather than relying on traditional media to communicate their messages, the blocs have utilised public diplomacy tools to better inform a global audience.

E-diplomacy tools have allowed Pacific parties to become more innovative in their diplomacy. The six main blocs each have comprehensive and lively websites that publicise current news, meetings, partnership information, podcasts, and negotiating positions on particular issues. They hold a wealth of information, with archival documents from speeches, position papers, and country reports. Social media, through Facebook, YouTube and Twitter accounts, has facilitated dialogue with a global audience. The Twitter accounts of Marlene Moses (the Nauruan ambassador and former chair of AOSIS), Tony De Brum, the LDC chair, and G77 chair have a combined following in excess of 15,000. The tools of e-diplomacy have also been used to support the civil society climate activism of such organisations as 350.org, Pacific 350, and Peoples Climate March (Visenten 2014). And who can forget Kathy Jetnil-Kijine, the Marshallese poet who brought world leaders to tears at the UN Climate Summit, who now has more than 500,000 views on YouTube?

A further development in the role of e-diplomacy is the use of contracted professional negotiation and public relation firms. Experts in public relations have trained coalition members, and some have been placed as short-term contracted spokespersons, to ensure coalition members are able to communicate effectively to the global media. Public relations firms have ensured that various coalition key positions are communicated in both traditional and social media forms in a timely and effective manner. A notable firm within the negotiator circles is the Independent Diplomat, used by the Republic of Marshall Islands, AOSIS, and the Cartagena Group. This group of independent former diplomats, 
international lawyers, and international relations experts has been associated with the blocs since 2009, providing diplomatic support, advice and technical assistance on the 'legal form' for the post-2012 climate regime, including the future of the Kyoto Protocol.

\section{Conclusion}

Despite the importance of coalitions in climate change negotiations, there remains a lacuna in the literature on coalition-building and coalition diplomacy in the regime more broadly. More importantly, there is little empirical research on the diplomacy of Pacific states in these coalitions and the regime, despite their being among the states that are the most vulnerable, sensitive, and susceptible to the effects of climate change. While this chapter is purely conceptual in highlighting the literature and trends of Pacific state participation in UNFCCC coalitions thus far, it emphasises the potential, and the need, for students of diplomatic studies to research the phenomenon. One such area for future empirical work is exploring the intra-coalition politics of Pacific states and their coalition allies.

It is undeniable that the global political landscape of coalition blocs is complex, adding to an already complex climate change regime. The two decade-long regime has evolved and become more complex, with more actors and issues. In respect of the diplomacy of interstate coalitions, this chapter argues that, as climate change negotiations have evolved and processes matured, so too have the diplomatic capabilities of Pacific states.

According to Dupont, coalition blocs function to allow states to manage the complex regime and to maximise their power. They function as a clearinghouse for common positions with parties with similar economic development concerns, and provide a space for dialogue with developed countries, and, more importantly, to highlight small islands development needs. By joining coalitions, Pacific states have become better equipped to navigate the regime, giving them a louder voice to affirm their vulnerabilities, and build resilience to climate change. The coalitions have empowered Pacific states and their leaders in their diplomatic finesse by providing access to a wide network of negotiators, the capability to employ climate leadership, and the utility of public diplomacy tools to inform their citizens and a wider global audience on climate issues.

However, frustrations remain, and the increasing rhetoric has been that the regime and blocs have not delivered on Pacific-specific and coral atoll nation needs. This in turn has motivated Pacific leaders to create new vehicles, such as the PSIDS, to bring a united Pacific voice to the fore in climate change 
negotiations. The emergence of Pacific blocs can therefore be seen as a natural progression in the global dialogue on climate change, as Pacific states develop their capacity and capability as agents of change. The participation of Pacific states in wider coalitions, and the formation of their own, is striking evidence of the new Pacific diplomacy, driven in this case by the urgency of the issue in the Pacific Islands - where it is one of survival - and by the wide divergence between the climate change positions of the forum island states and those of Australia and New Zealand. Although the emergence of the PSIDS and CANCC is at the fringes of UNFCCC attempts to address these concerns, only time will tell if these blocs become a force to be reckoned with in climate negotiations.

\section{References}

Ashe, J.W., R. Van Lierop and A. Cherian, 1999, 'The Role of the Alliance of Small Island States (AOSIS) in the Negotiation of the United Nations Framework Convention on Climate Change (UNFCCC)', Natural Resources Forum 23(3), pp. 209-20.

Audet, R., 2013, 'Climate Justice and Bargaining Coalitions: A discourse analysis', International Environmental Agreements: Politics, law and economics 13(3), pp. 369-86.

Bailer, S., 2012, 'Strategy in the Climate Change Negotiations: Do democracies negotiate differently?', Climate Policy 12(5), pp. 534-51.

Betzold, C., 2010, “"Borrowing” Power to Influence International Negotiations: AOSIS in the climate change regime, 1990-1997', Politics 30(3), pp. 131-48.

Betzold, C., P. Castro and F. Weiler, 2012, 'AOSIS in the UNFCCC Negotiations: From unity to fragmentation?', Climate policy 12(5), pp. 591-613.

Blaxekjær, L.Ø. and T.D. Nielsen, 2014, 'Mapping the Narrative Positions of New Political Groups under the UNFCCC,' Climate Policy 14, pp. 1-16.

Chasek, P.S., 2005, 'Margins of Power: Coalition building and coalition maintenance of the South Pacific Island States and the Alliance of Small Island States', Review of European Community and International Environmental Law 14(2), pp. 125-37.

Chasek, P.S. and L. Rajamani, 2003, 'Steps toward Enhanced Parity: Negotiating capacity and strategies of developing countries', in I. Kaul (ed.), Providing Global Public Goods: Managing Globalization, United Nations Development Project, Oxford University Press, New York. 
Climate Vulnerable Forum, n.d., 'About the Climate Vulnerable Forum'. Available at: www.thecvf.org/web/climate-vulnerable-forum/.

Depledge, J., 2005, The Organization of Global Negotiations: Constructing the climate change regime, Earthscan, Sterling.

Dupont, C., 1996, 'Negotiation as Coalition Building', International Negotiation $1(1)$, pp. 47-64.

Figueres, C., 2014, 'Christiana Figueres Addresses 2014 Climate Leadership Conference'. Available at: www.youtube.com/watch?v=6loTK3FI_fQ.

Gough, C. and S. Shackley, 2001, 'The Respectable Politics of Climate Change: The epistemic communities and NGOs', International Affairs 77(2), pp. 329-46.

Gupta, J., 2000, On Behalf of My Delegation: A survival guide for developing country climate negotiators, Center for Sustainable Development of the Americas International Institute for Sustainable Development, Washington, D. C.

Holbraad, C., 1971, 'The Role of Middle Powers', Cooperation and Conflict 6(1), pp. 77-90.

Islands Business, 2014, 'Cartagena Group Expresses Climate Action Optimism: Marshall Islands Foreign Minister', Suva, Fiji.

Johnson, G., 2014, 'Majuro Cartagena Dialogue Wraps Up, Optimism Expressed,' Pacific Islands Report, April 7. Available at: pidp.org/pireport/2014/ April/04-07-06.htm.

Least Developing Countries Group, n.d., 'LDC Group at UN Climate Change Negotiations'. Available at: ldcclimate.wordpress.com/about-the-ldc-group/.

Morgenthau, H.J., 2003, Politics Among Nations: The struggle for power and peace, McGraw-Hill Education, New York.

Narlikar, A., 2003, International Trade and Developing Countries: Bargaining and coalitions in the GATT and WTO, Routledge, New York.

Pacific negotiator, 2014, personal communication with Pacific Negotiator, 2 September.

Packard, A., 2010, 'Kiribati Climate Change Conference Calls for Urgent Cash and Action', Guardian, November 6.

Sheehan, M., 1996, The Balance of Power: History and theory, Routledge, London.

Snyder, G.H., 1997, Alliance Politics, Cornell University Press, Ithaca. 
United Nations (UN), 2014, 'SIDS Accelerated Modalities of Action [S.A.M.O.A.] Pathway: Outcome of the Third International Conference on Small Island Developing States, 1-4 September 2014, Samoa'. Available at: www.sids2014. org/index.php?menu=1537.

United Nations Framework Convention on Climate Change (UNFCCC), n.d. 'Party Groupings'. Available at: unfccc.int/parties_and_observers/parties/ negotiating_groups/items/2714.php.

UNFCCC, n.d., 'UNFCCC Basic Facts and Figures'. Available at: unfccc.int/ essential_background/basic_facts_figures/items/6246.php.

von videoarchitekt, K., 2007, 'Moment of the "Bali Break Through"'. Available at: www.youtube.com/watch?v=F-Glv--DONM.

Visentin, L., 2014, 'Poet Brings World Leaders to Tears at UN Climate Summit', Sydney Morning Herald, 25 September.

Wallbott, L. and N. Deitelhoff, 2012, 'Beyond Soft Balancing: Small states and coalition-building in the ICC and climate negotiations', Cambridge Review of International Affairs 25(3), pp. 345-66.

Walt, S.M., 1987, The Origins of Alliance, Cornell University Press, New York.

Waltz, K.N., 1979, Theory of International Politics, Addison-Wesley, Reading, Massachusetts.

Yamin, F. and J. Depledge, 2004, The International Climate Change Regime: A guide to rules, institutions and procedures, Cambridge University Press, New York. 
This text is taken from The New Pacific Diplomacy, edited by Greg Fry and Sandra Tarte, published 2015 by ANU Press, The Australian National University, Canberra, Australia. 